\title{
Micronutrients: oxidant/antioxidant status
}

\author{
Patricia Evans ${ }^{1} *$ and Barry Halliwell ${ }^{2}$ \\ ${ }^{1}$ Department of Haematology, Royal Free and University College Medical School, University College London, \\ 98 Chenies Mews, London WClE 6HX, UK \\ ${ }^{2}$ Department of Biochemistry, National University of Singapore, Kent Ridge Crescent, Singapore 119260
}

\begin{abstract}
Potentially damaging species (reactive oxygen, nitrogen and chlorine species) arise as byproducts of metabolism and as physiological mediators and signalling molecules. Levels of these species are controlled by the antioxidant defence system. Several components of this system are micronutrients (e.g. vitamins $\mathrm{C}$ and $\mathrm{E}$ ) or are dependent upon dietary micronutrients (e.g. $\mathrm{CuZn}$ and $\mathrm{Mn}$ superoxide dismutase). The antioxidant defences act as a coordinated system where deficiencies in one component may affect the efficiency of the others. Oxidative stress may be an important factor in infection if micronutrients are deficient.
\end{abstract}

Oxidative stress: Antioxidants: Micronutrients

That nutrition and health are intimately linked has been known since ancient times. We now realise the vital importance of micronutrients to health and that several micronutrients have antioxidant roles. These may be as direct antioxidants such as vitamins $\mathrm{C}$ and $\mathrm{E}$, or as components of antioxidant enzymes: superoxide dismutase $(\mathrm{Mn}, \mathrm{Cu}, \mathrm{Zn})$ or glutathione peroxidase (Se). It is now widely believed that diet-derived antioxidants play a role in the prevention of human disease and that deficiencies may prejudice fetal and childhood development.

\section{What do antioxidants protect us against?}

Several potentially damaging species (often termed reactive oxygen, nitrogen and chlorine species, ROS/RNS/RCS, Table 1) arise as by-products of normal metabolism and from chemical accidents (Halliwell \& Gutteridge, 1999). Superoxide $\left(\mathrm{O}_{2}^{-}\right)$is a one-electron reduction product of molecular oxygen that is formed during normal respiration in mitochondria and by autoxidation reactions. The electron transport chain is not completely secure and electrons may leak onto molecular oxygen prior to their transfer to cytochrome oxidase forming $\mathrm{O}_{2}^{--}$.

Hydrogen peroxide $\left(\mathrm{H}_{2} \mathrm{O}_{2}\right)$ is another ROS formed during normal metabolism. Much is produced in the brain during the catalytic degradation of neurotransmitters such as dopamine. Monamines such as dopamine are also able to autoxidise producing both $\mathrm{O}_{2}^{-}$and $\mathrm{H}_{2} \mathrm{O}_{2}$ (Bindoli et al.1992). About $3 \%$ of the body's haemoglobin also autoxidises daily to produce these substances (Winterbourn, 1985).
Not all ROS/RNS/RCS production is accidental, however, since the body can use these substances for its own benefit. Nitric oxide (NO) finds a multiplicity of uses, for example as a regulator of vascular tone and as a messenger in the central nervous system (Bredt, 1999). Production of reactive species by activated neutrophils, macrophages and several other cell types is used in bacterial killing. Indeed ROS/RNS/RCS may have a variety of functions including regulation of gene expression (Jabs, 1999) and induction of apoptosis (Stewart, 1994): programmed cell death involved in fetal development and tissue remodelling where changes in the type and distribution of tissues occur. An involvement of ROS in the process of cell differentiation has been suggested on the basis of studies with the slime mould and Neurospora crassa (Toledo et al.1994). In both cases differentiation appears to be accompanied by increased production of ROS. Indeed, addition of antioxidants can modulate the process. Rat embryos grown under zincdeficient conditions show different patterns of apoptosis in tissue remodelling during fetal development compared to their zinc-sufficient counterparts (Jankowski et al.1995). Areas of apoptosis stain positive when treated with an agent able to detect oxidative stress (Keen, 2000, unpublished). It is clear from this that ROS/RNS/RCS are intimately involved in normal physiology and are important in fighting infection. However, the ability of radicals such as $\mathrm{NO}^{\circ}$ and $\mathrm{O}_{2}^{-}$to kill invading bacteria means that these substances are also capable of damaging normal tissues.

Local uncontrolled production of ROS/RNS/RCS occurs in several diseases which indicates how damaging these species can be. Examples are inflammatory conditions such

\footnotetext{
Abbreviations: ROS, reactive oxygen species; RNS, reactive nitrogen species; RCS, reactive chlorine species; CuZnSOD, copper zinc superoxide dismutase; MnSOD, manganese superoxide dismutase; LDL, low density lipoprotein; TBARS, thiobarbituric acid reactive substance; NEC, necrotising enterocolitis; BPD, bronchopulmonary dysplasia.

* Corresponding author: Dr Patricia Evans, fax +44 0207209 6222, email patricia.evans@ucl.ac.uk
} 
Table 1. Reactive oxygen and nitrogen species produced in the human body

\begin{tabular}{ll}
\hline $\begin{array}{l}\text { Reactive oxygen species (ROS) } \\
\text { Radicals }\end{array}$ & \multicolumn{1}{c}{$\begin{array}{c}\text { Non-radicals } \\
\text { Superoxide, } \mathrm{O}_{2}^{--}\end{array}$} \\
Hydroxyl, $\mathrm{OH}^{*}$ & Hydrogen peroxide, $\mathrm{H}_{2} \mathrm{O}_{2}$ \\
Peroxyl, $\mathrm{RO}_{2}$ & Ozochlorous acid, $\mathrm{HOCl}$ \\
Alkoxyl, $\mathrm{RO}^{-}$ & Singlet oxygen, ${ }^{1} \Delta \mathrm{g}$ \\
Hydroperoxyl, $\mathrm{HO}_{2}$ & Hypobromous acid, $\mathrm{HOBr}$
\end{tabular}

Reactive nitrogen species (RNS) $\dagger$ Radicals

Nitric oxide, NO

Nitrogen dioxide, $\mathrm{NO}_{2}$

Non-radicals
Nitrous acid, $\mathrm{HNO}_{2}$
Nitrosyl cation, $\mathrm{NO}^{+}$
Nitroxyl anion, $\mathrm{NO}^{-}$
Dinitrogen tetroxide, $\mathrm{N}_{2} \mathrm{O}_{4}$
Dinitrogen trioxide, $\mathrm{N}_{2} \mathrm{O}_{3}$
Peroxynitrite, $\mathrm{ONOO}^{-}$
Nitronium cation, $\mathrm{NO}_{2}^{+}$
Nitryl chloride, $\mathrm{NO}_{2} \mathrm{Cl}$
Alkyl peroxynitrates, $\mathrm{ROONO}^{-}$
Nitroxyl anion, $\mathrm{NO}^{-}$

Reactive chlorine species (RCS)

\begin{tabular}{|c|c|}
\hline & \begin{tabular}{l}
\multicolumn{1}{c}{ Non-radicals } \\
Hypochlorous acid, $\mathrm{HOCl} \ddagger$ \\
Nitryl chloride, $\mathrm{NO}_{2} \mathrm{Cl}$
\end{tabular} \\
\hline $\begin{array}{l}\text { * } \mathrm{ROS} \text { is a collective term which includ } \\
\text { non-radicals that are oxidising agent } \\
\text { radicals. } \\
+\mathrm{RNS} \text { includes both nitrogen containing } \\
\text { nitrite can be regarded as a } \mathrm{ROS} \text { or } \mathrm{R} \\
\text { \# Some species, e.g. } \mathrm{HOCl} \text { are both } \mathrm{RO} \\
\text { These species have widely varying react } \\
\text { everything, whereas } \mathrm{H}_{2} \mathrm{O}_{2}, \mathrm{O}_{2}^{--}, \mathrm{NO}^{-} \text {on } \\
\mathrm{RO}_{2}, \mathrm{RO}, \mathrm{HOCl}, \mathrm{HOBr}, \mathrm{NO}_{2} \mathrm{Cl}, \mathrm{NO}_{2} \text {, } \\
\text { reactivities. }\end{array}$ & $\begin{array}{l}\text { es both oxygen radicals and certain } \\
\mathrm{S} \text { and/or are easily converted into } \\
\text { radicals and non-radicals. Peroxy- } \\
\mathrm{NS} \text {. } \\
\mathrm{S} \text { and } \mathrm{RCS} \text {. } \\
\text { vities: } \mathrm{OH} \text { reacts rapidly with almost } \\
\text { ly react quickly with a few molecules. } \\
\mathrm{ONOO}^{-} \text {and } \mathrm{O}_{3} \text { have intermediate }\end{array}$ \\
\hline
\end{tabular}

as inflammatory bowel disease and rheumatoid arthritis (Halliwell \& Gutteridge, 1999). Here inflammatory cells exude $\mathrm{O}_{2}^{--}, \mathrm{H}_{2} \mathrm{O}_{2}, \mathrm{HOCl}$ and probably $\mathrm{NO}^{-}$in response to local inflammatory stimuli. The limited in vitro reactivity of ROS/RNS such as $\mathrm{O}_{2}^{-}$and NO makes it unlikely that they could directly inflict the kind of tissue damage seen in these conditions. It is thought that transition metal ions released during tissue damage might catalyse the conversion of these poorly cytotoxic species into much more harmful substances.

One example is:

$$
\underbrace{\mathrm{Fe}^{2+}+\mathrm{H}_{2} \mathrm{O}_{2}}_{\text {ascorbate, } \mathrm{O}_{2}^{--}} \rightarrow \mathrm{Fe}^{3+}+\mathrm{OH}^{-}+\mathrm{OH}
$$

Free radicals such as $\mathrm{OH}$ are highly damaging to the major biomolecules and could cause the type of damage seen in rheumatoid arthritis and inflammatory bowel disease. Hydroxyl radical causes strand breaks and base modification in DNA leading to changes in gene expression, mutation and apoptosis. Protein side chains are oxidised which can result in enzyme, receptor and carrier dysfunction. Lipid peroxidation alters functional properties of membranes and delivery of lipids to tissues (Halliwell, 1996a). Thus production of ROS/RNS/RCS may have extremely deleterious effects and is counteracted by the antioxidant defences under normal circumstances in healthy individuals.

\section{Antioxidant defences and oxidative stress}

The antioxidant defences consist of low molecular mass antioxidants such as vitamins $\mathrm{C}$ and $\mathrm{E}$ and enzymes, e.g. superoxide dismutase (Fig. 1). Their function is to act as a coordinated and balanced system to protect tissues and body fluids from damage by ROS/RNS/RCS whether produced physiologically or as a response to inflammation, infection or disease.

Many antioxidant defences depend on micronutrients or are micronutrients themselves (Table 2). Examples of the latter are vitamin $\mathrm{E}$ (protects against lipid peroxidation) and vitamin C (scavenges some ROS/RNS/RCS directly and probably recycles vitamin $\mathrm{E}$ ). Superoxide dismutase (a $\mathrm{CuZn-}$ or Mn-containing enzyme) removes $\mathrm{O}_{2}^{--}$by converting it to $\mathrm{H}_{2} \mathrm{O}_{2}$ which is then removed by glutathione peroxidase (a GSH-dependant selenoprotein) or catalase (a haem enzyme). The iron-transporting protein transferrin is normally kept at around $30 \%$ iron saturation to ensure that no iron is available to catalyse formation of dangerous radicals such as $\mathrm{OH}$ (Halliwell \& Gutteridge, 1992).

Antioxidant defences act as a balanced and coordinated system and each relies on the action of the others. For instance, the survival time of rats exposed to pure oxygen was increased by about $70 \%$ when liposomes containing both catalase and SOD were injected intravenously before and during exposure. Liposomes containing either enzyme alone were much less protective (Turrens et al.1984).

In health, the balance between ROS/RNS/RCS and the antioxidant defences lies slightly in favour of the reactive species so that they are able to fulfil their biological roles. Repair systems take care of damage which occurs at a low level even in healthy individuals (Halliwell, 1996b). Oxidative stress occurs when there is a change in this balance in favour of ROS/RNS/RCS and may occur in several circumstances, for instance in disease or malnutrition where there are insufficient micronutrients to meet the needs of the antioxidant defences (Zidenberg-Cherr \& Keen, 1991). Oxidative stress can be significant especially if the individual is exposed to environmental challenges which increase the production of reactive species above normal levels, for instance, infection. Examples of this are in Keshan disease and kwashiorkor. Keshan disease, resulting from dietary selenium deficiency, follows seasonal variations in incidence which may be related to infection with Coxsackie virus (Beck et al. 1995). If plasma selenium levels fall below $1 \mu \mathrm{M}$, levels of glutathione peroxidase fall (Diplock, 1993) but only have clinically significant effects (cardiomyopathy) when infection with Coxsackie virus occurs (Beck et al. 1995). The incidence of kwashiorkor increases following measles epidemics and may be precipitated in severe malnutrition by a sudden intense oxidative stress caused by infection (Golden et al. 1991). Red cell glutathione and glutathione peroxidase levels are low and there are also lower plasma levels of vitamins A and E, carotene, zinc, copper, selenium as well as albumin, transferrin and caeruloplasmin. Low 


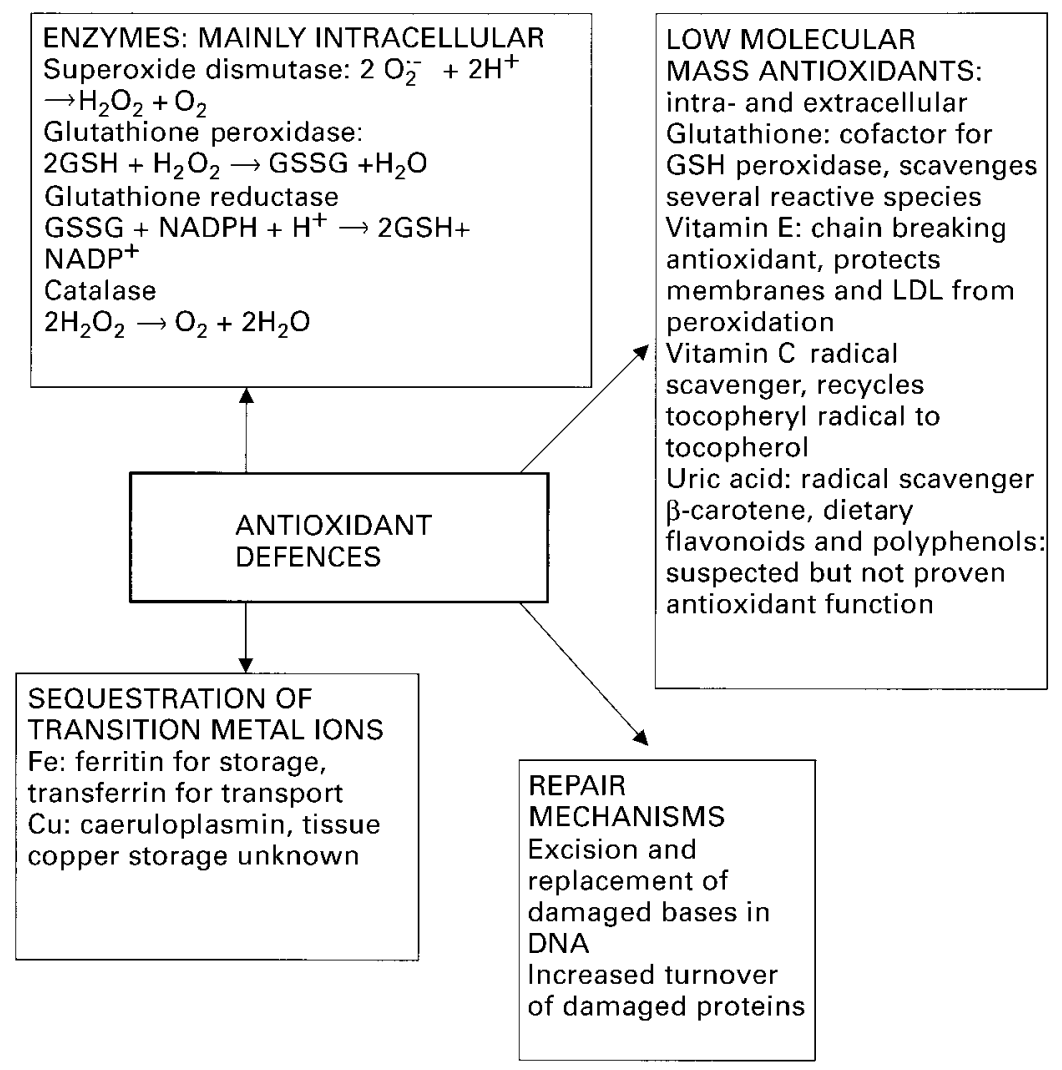

Fig. 1. Summary of antioxidant defences in the human body.

molecular mass iron catalytic for free radical production is also present in the plasma.

\section{Influence of micronutrient levels on the antioxidant defences}

The antioxidant defences rely heavily on vitamins and minerals in the diet (Table 2) as well as essential amino acids required to synthesise glutathione and antioxidant proteins such as albumin. There have been few direct studies on the relationship between micronutrient deficiencies and oxidative stress. Oxidative stress should be evaluated by looking at the whole spectrum of antioxidants and at biomarkers of oxidative damage. Once evaluated, it can then be correlated with levels of individual micronutrients. In kwashiorkor, extreme protein-energy deficiency produces readily measurable parameters of oxidative stress whereas in marginal undernourishment,

Table 2. Links between dietary constituents and oxidative stress

\section{Direct link}

Antioxidant nutrients: Vitamins $\mathrm{C}$ and $\mathrm{E}$, possibly carotenoids, flavonoids and plant polyphenols

\section{Indirect link}

$\mathrm{Fe}$

$\mathrm{Mn}$

$\mathrm{Cu}$

$\mathrm{Zn}$

$\mathrm{Mg}$

Proteins

Riboflavin

Thiamine

Selenium

Nicotinamide

Folic acid
Catalase, prevention of hypoxia in haemo/myoglobin

Nitric oxide synthase (NO often has antioxidant properties)

MnSOD

CuZnSOD, caeruloplasmin, normal iron metabolism

CuZnSOD, metallothionein, membrane stabilisation, displacement of iron

Cofactor in pentose-phosphate pathway

No specific link to antioxidant defence but severe deficiencies cause oxidative damage specially to the heart

Provide amino acids for synthesis of antioxidant defence enzymes, GSH and albumin (as sacrificial antioxidant protein) Glutathione reductase (FAD cofactor)

Required for transketolase in the pentose phosphate pathway

Glutathione peroxidase, selenoprotein $\mathrm{P}$, other selenoproteins

$\mathrm{NAD}^{+}, \mathrm{NADP}^{+}, \mathrm{NADPH}, \mathrm{NADH}$, energy metabolism, repair of DNA, poly (ADP ribose) polymerase, glutathione reductase, maintaining catalase function

Minimises level of plasma homocysteine - high levels are a risk factor for cardiovascular disease perhaps by oxidative damage to the vascular endothelium 
changes are likely to be more subtle and variable, depending on which micronutrients are deficient.

In view of these and other difficulties, studies relating micronutrient deficiency to oxidative stress, have largely been carried out in laboratory animals. In these studies, a single micronutrient or pair of micronutrients has been excluded from the diet and effects on various aspects of the antioxidant defences, or a biomarker of damage, measured.

\section{Individual micronutrients}

\section{Zinc}

Studies on most micronutrients are complicated by the fact that the nutrient is multi-functional. For example, zinc is required in over 200 enzymes and so deficiency is likely to affect a number of different systems. Zinc, like copper, is a component of CuZn-superoxide dismutase (CuZnSOD), an important antioxidant enzyme. Deficiencies in copper rather than zinc (Zidenberg-Cherr \& Keen, 1991) affect the activity of this enzyme. Zinc has a stabilising effect on membranes possibly by displacing bound transition metal ions and thereby preventing peroxidation of membrane lipids (Bettger et al. 1980). Zinc-deficient rats have reduced serum zinc, lower levels of alkaline phosphatase and erythrocytes with raised glutathione-S-transferase levels and lowered glutathione concentrations (Kraus et al. 1997). Olin et al. (1993) found that restricting maternal dietary zinc causes DNA strand breaks and increased 8-hydroxy$2^{\prime}$-deoxyguanosine levels in infant monkeys, although levels of several antioxidant enzymes remained unaltered. Some reports propose zinc to be anti-atherogenic through either its inhibition of low density lipoprotein (LDL) oxidation (Wilkins \& Leake, 1994) or its role in inhibition of the oxidative stress responsive factors involved in destruction of vascular endothelial cell integrity (Hennig et al. 1996). Severe and moderate zinc deficiency has been found to cause oxidative damage to proteins, lipids and DNA in rat testes (Oteiza et al. 1995) which may be due to iron accumulation or a reduction in zinc-dependent antioxidant processes. However, Taylor et al. (1988) report that the antioxidant defences were not seriously compromised in the liver and lungs of zinc-deficient rats.

\section{Magnesium}

Magnesium, like zinc, is also involved in many physiological processes, particularly reactions involving ATP. There are several reports of generation of ROS in magnesium-deficiency. Rayssiguier et al. (1993) reviewed the evidence that magnesium-deficient animal tissues show increased susceptibility to lipid peroxidation, which is alleviated by coincubation with antioxidants suggesting that free radicals are involved. Magnesium deficiency appears to potentiate ischaemia-reperfusion injury another effect where added vitamin $\mathrm{E}$ was protective (Kramer et al. 1994). Magnesium and copper deficiency has been postulated to play a role in the retinopathy of prematurity through reduction in protective antioxidant enzyme activity (Caddell, 1995).

Necrotising enterocolitis (NEC) is a neonatal disorder of unknown cause characterised by rapid bowel necrosis (Caddell, 1996a). It is the most common gastro-intestinal emergency in neonatal intensive care units and is a worldwide problem. Its incidence is inversely proportional to birth weight and degree of maturity. Infants born at or before 28 weeks gestational age have still not received $80 \%$ of magnesium or $67 \%$ of copper expected at term. NEC has been regarded as a luminal insult that causes local intense generation of free radicals. Although its aetiology is unknown, there is some evidence to implicate magnesium and possibly copper deficiency (reviewed in Caddell, 1996a).

Bronchopulmonary dysplasia (BPD) will affect about $50 \%$ of very low birth weight infants who survive 28 days and may involve magnesium deficiency as about $80 \%$ of fetal magnesium accumulation occurs in the third trimester of pregnancy (Caddell, 1996b). Amongst several agents increasing in BPD are oxygen free radicals. Magnesium deficiency seems to increase the susceptibility of cells and tissues to peroxidation. Because of the difficulty of studying very low birth weight neonates and the danger of magnesium toxicity, little is known about supplementation of this group.

\section{Manganese}

Manganese is a component of several enzymes involved in fatty acid and cholesterol biosynthesis as well as mitochondrial Mn-SOD. There are few well-described cases of manganese deficiency in the medical literature. ZidenbergCherr et al. (1983) measured Mn-SOD activities in manganese sufficient and deficient rats from birth to 60 days of age. Both groups showed an increase in activity although this increase was much lower in the deficient rats. Measurements of thiobarbituric acid-reactive substances (TBARS - a non-specific measure of lipid peroxidation) under conditions of oxidative stress suggested higher than normal levels of lipid peroxidation in deficient rats which may contribute to the damage to mitochondrial membranes observed in manganese-deficient animals. Zidenberg-Cherr et al. (1991) showed that increases in levels of MnSOD, $\mathrm{CuZnSOD}$ and glutathione peroxidase in response to ozone exposure in normal mice were not paralleled in manganesedeficient mice.

Gene knockout techniques have been used to generate mice completely lacking in MnSOD. In one study, all such mice died within 10 days with cardiac abnormalities, fat accumulation in the liver and skeletal muscle and metabolic acidosis (Melov et al. 1998). The lethal nature of MnSOD knockout shows how important this enzyme is in removing $\mathrm{O}_{2}^{--}$. MnSOD-deficient strains which survive longer succumb to a variety of pathologies including severe anaemia and neurodegeneration (Lebovitz et al. 1996).

\section{Iron}

Although iron overload diseases are generally regarded as examples of diseases involving oxidative stress (Young et al. 1994), iron deficiency has also been associated with increased production of ROS. Rao and Jagadeesen (1996) showed that, on feeding rats carcinogens, iron deficiency 
rendered the rat more susceptible to tumorigenesis by a mechanism involving oxidative stress. Erythrocytes from patients with iron deficiency anaemia are more sensitive to agents able to induce oxidative stress (Bartal et al. 1993). Kwik-Uribe et al. (1999) investigated marginal iron deficiency, a common nutritional disorder. Iron deficiency is associated with neurobehavioural deficits presumably due to high iron demand by the brain tissue. Oxidative stress was suggested by elevation in TBARS in the cerebellum of marginally iron deficient animals who showed lower body weights and grip responses than normal animals. Severely anaemic rats have significant elevations in the levels of breath ethane and liver and kidney malondialdehyde measured by gas chromatography-mass spectrometry (Knutson et al. 1999). Ethane and malondialdehyde are more specific markers of lipid peroxidation than TBARS. Daily iron supplementation resulted in increased lipid peroxidation and abnormal iron accumulation. However, intermittent supplementation (once every 3 days) alleviated these effects.

\section{Copper}

Oxidative stress has been postulated to contribute to the pathology associated with copper deficiency. Copper is required for caeruloplasmin, which loads iron onto transferrin, as well as for CuZnSOD. Erythrocyte CuZnSOD has been reported to diminish in copper deficiency with a rise in spectrin protein carbonyls (Sukalski et al. 1997). However, others report that CuZnSOD only decreases in liver, not in erythrocytes (Dashti et al. 1995). These decreases are not apparently paralleled by concomitant increases in TBARS. Supplementing copper deficient rats with dimethyl sulphoxide inhibited cardiac hypertrophy, anaemia and depression in cardiac copper levels, which occur in copper deficiency, indicating that $\mathrm{OH}$ might contribute to cardiovascular effects of copper deficiency (Saari, 1989).

\section{Vitamins C and E: micronutrients directly involved in the antioxidant defences}

Like most micronutrients, vitamin $\mathrm{C}$ plays a variety of roles. Its reactivity with ROS/RNS and concentrations in human fluids and tissues make it a likely scavenger of these species (Halliwell, 1996b). It is also thought to be involved in recycling the $\alpha$-tocopheryl radical back to $\alpha$-tocopherol (Halliwell \& Gutteridge, 1999). Several epidemiological studies of the relationship between intake of vitamins $\mathrm{C}$ and $\mathrm{E}$ and cardiovascular disease have been carried out. The Nurses' Study (Colditz et al. 1997) attempted to relate antioxidant consumption to coronary disease. Only long term ( $>2$ years) consumption of vitamin $E$ was associated with lower risk. There was no relation between risk and vitamin $\mathrm{C}$ intake although consumption was above the lowest quintile of the US RDA, i.e. levels of vitamin C may have been too high to show any effects in this study. The First National Health and Nutrition Examination Study (NHANES-1) reported that the cardiovascular disease mortality rate was $34 \%$ lower than average among participants with the highest vitamin $\mathrm{C}$ intake (Enstrom et al. 1992). No other antioxidants were assessed in this study. In 1986, the US Health Professionals' study registered that a lower cardiovascular disease risk was observed amongst men with a higher calculated dietary vitamin E intake (Buring \& Hennekens, 1997). There was no apparent lowering of risk with increased amounts of vitamin $\mathrm{C}$ in the diet but the population studied was relatively well nourished.

The Euramic study (a European multicentre study) showed no inverse correlation in vitamin $\mathrm{E}$ levels and numbers of heart attacks in the population studied (Kardinaal et al. 1993). However, a study in Scotland (Riemersma et al. 1991) revealed lower vitamin E concentrations in plasma of patients having angina pectoris than in control subjects. However, vitamin $C$ and $\beta$ carotene levels were lower overall, as many of the patients were smokers. The CHAOS (Cambridge Heart Antioxidant) study (Stephens et al. 1996) showed that vitamin E supplementation reduced the incidence of non-fatal myocardial infarctions by $50 \%$ although there was no effect of vitamin E supplementation on fatal infarctions.

The GISSI-Prevenzione (GISSI-Prevenzione investigators, 1999) showed no protection against cardiovascular disease risk with vitamin E supplementation. A viewpoint on the paradoxical results of the CHAOS and GISSIPrevenzione trials relating to patient backgrounds is given in Halliwell (2000). It is generally believed that increased levels of vitamin $\mathrm{E}$ protect against cardiovascular disease. At present, there is insufficient evidence to correlate levels of vitamin $\mathrm{C}$ with lower risk of cardiovascular disease.

Similarly, evidence for protection from cancer by vitamins $\mathrm{C}$ and $\mathrm{E}$ is not compelling although lower levels of vitamin $\mathrm{C}$ may be a risk factor for gastric cancer (Halliwell \& Gutteridge, 1999).

\section{Pro-oxidant effects - can supplementation ever be dangerous?}

The Fenton reaction conveys to us that iron could be a prooxidant and that is why iron is sequestered within storage or transport proteins and does not normally exist in a low molecular mass form. Iron deficiency as well as iron overload seems to involve a degree of oxidative stress (as cited previously). Iron supplementation should be considered carefully as it may give rise to adverse effects, for instance it increases lipid peroxidation if given daily to rats (Knutson et al. 1999). Hyposideraemia in patients with cancer or chronic infections may be a defence mechanism, breaking the immunity by iron administration can cause relapses in tuberculosis, brucellosis and malaria (Reizenstein, 1991). While iron deficiency anaemia should be treated, there are good reasons to avoid excessive iron supplementation.

Ascorbic acid is a potent reducing agent and is often used in vitro to reduce iron in Fenton type reactions (Udenfriend et al. 1954). Could ascorbate act as a pro-oxidant in reducing iron in vivo? Most evidence, albeit indirect, points to a role for ascorbate as an antioxidant (Halliwell, 1996b) in healthy people. However, serious cardiovascular disturbances have been reported when excess ascorbic acid was given to iron-overloaded patients (McLaran et al. 
1982; Rowbotham \& Roeser, 1984) who may represent a population at risk in ascorbate supplementation. However, there was no evidence to implicate a pro-oxidant effect of ascorbate. High doses of vitamin C (500 mg/day) plus iron can cause certain oxidative base modifications in DNA extracted from leucocytes of healthy human donors (Rehman et al. 1998). However, the significance of this is unknown.

Although there is an evidence of on-going oxidative damage to DNA, lipids and proteins even in healthy individuals (Halliwell, 1996a), there is no evidence that pro-oxidant effects of ascorbate are responsible. Data suggest that there may be no extra benefit from large intakes.

\section{Does oxidative stress affect susceptibility to infection?}

Micronutrient deficiency leads to increased incidence of infection. Many researchers review the association between oxidative stress and infection (some reviews include Pace \& Leaf, 1995, Peterhans, 1997, Postma et al. 1996, Schwarz, 1996). However, all infections cause inflammation which will inevitably involve a degree of oxidative stress. Micronutrients contributing to the antioxidant defences also contribute to the immune response. These two systems work together and it is clear that in micronutrient deficiency, both systems can be compromised to an extent depending on the degree and nature of the deficiency. Very little work has been done relating to the effects of deficiencies to oxidative stress and immune function both of which are likely to influence susceptibility to infection. Micronutrients such as zinc, copper, selenium and iron are involved in both the inflammatory and immune systems. Infection activates these two systems both of which will be depressed by nutritional deficiencies. It is therefore likely that nutritional deficiencies underlie the different presentations of diseases such as measles in Europe and Africa. In Europe, measles is relatively benign whereas in Africa the disease has a high mortality rate. Thus, severely malnourished populations may constitute a group which is more susceptible to the damaging effects of oxidative stress.

Oxidative stress is implicated in the pathogenesis of several viral infections, including hepatitis, influenza and AIDS (Semba \& Tang, 1999). Dietary deficiency in selenium or vitamin $\mathrm{E}$ allows a normally benign coxsackie virus $\mathrm{B} 3$ to convert to virulence by a change in the nucleotide sequence in the genome of the benign virus and cause heart damage (Beck et al. 1995). However, it is not always the case that deficiency predisposes to infection. Iron deficiency may be protective to malaria and Yersinia infections, whereas iron overload may predispose to infection by supplying abundant iron for multiplying bacteria (Keusch, 1990). Low plasma or serum levels of vitamins A, E, B6, B12, C, carotenoids, selenium and zinc are common in many HIV-infected populations (Semba \& Tang, 1999) and may contribute to the pathogenesis of HIV infection through increased oxidative stress and compromised immunity.

\section{Conclusions}

It is often very difficult to correlate the biochemistry of a dietary deficiency with clinical symptoms that may arise because many vitamins and minerals have multiple roles in metabolism. Zinc is a known constituent of over 200 proteins (and possibly of other proteins as yet undiscovered!) which makes identification of lesions induced by its deficiency at the molecular level a prodigious task. Also cooperation exists between different elements of micronutrient metabolism implying that individual dietary constituents should not be studied in isolation. Zinc supplementation affects copper and iron homeostasis, for example (Sandstead, 1994). Nevertheless, relating effects of dietary deficiencies to biochemical activity is a major goal in understanding and alleviating malnutrition. The development of biomarkers to measure oxidative stress (Halliwell, 1999) means that more reliable and precise estimates of oxidative stress may be made. There is a need to measure these biomarkers in micronutrient deficient populations and correlate them to micronutrient status and infections. The picture, which emerges is that although micronutrient deficiencies may induce oxidative stress, this only becomes significant when infection or disease occurs. Although there is little evidence that ascorbate can act as a pro-oxidant, iron supplementation may cause lipid peroxidation in iron-deficient rats (Knutson et al. 1999). However, the mode of supplementation appears important and studies of different regimes of supplementation would be useful in humans.

\section{References}

Bartal M, Mazor D, Dvilansky A \& Meyerstein N (1993) Iron deficiency anaemia: recovery from in vitro oxidative stress. Acta Haematology 90, 94-98.

Beck MA, Shi Q, Morris VC \& Levander OA (1995) Rapid genomic evolution of a non-virulent coxsackie virus B3 in selenium-deficient mice results in selection of identical virulent isolates. Nature Medicine 1, 433-436.

Bettger WJ, Reeves PG, Savage JE \& O'Dell BL (1980) Interaction of zinc and vitamin E in the chick. Proceedings of the Society for Experimental Biology \& Medicine 163, 432-436.

Bindoli A, Rigobello MP \& Deeble DJ (1992) Biochemical and toxological properties of the oxidation products of catecholamines. Free Radical Biology and Medicine 13, 391-405.

Bredt DS (1999) Endogenous nitric oxide synthesis: biological functions and pathophysiology. Free Radical Research 31, 577-596.

Buring JE \& Hennekens CH (1997) Antioxidant vitamins and cardiovascular disease. Nutrition Reviews 55 (1 Pt 2), S53-S58.

Caddell JL (1995) Hypothesis: the possible role of magnesium and copper deficiency in retinopathy of prematurity. Magnesium Research 8, 261-270.

Caddell JL (1996a) A review of evidence for a role of magnesium and possibly copper deficiency in necrotizing enterocolitis. Magnesium Research 9, 55-66.

Caddell JL (1996b) Evidence for magnesium deficiency in the pathogenesis of bronchopulmonary dysplasia. Magnesium Research 9, 205-216.

Colditz GA, Manson JE \& Hankinson SE (1997) The Nurses' Health Study: 20-year contribution to the understanding of health among women. Journal of Women's Health 6, 49-62. 
Dashti SI, Thomson M \& Mameesh MS (1995) Effects of copper deficiency and copper complexes on superoxide dismutase in rats. Nutrition 11 (5 Suppl), 564-567.

Diplock AT (1993) Indexes of selenium status in human populations. American Journal of Clinical Nutrition 57 (2 Suppl), 256S-258S.

Enstrom JE, Kanim LE \& Klein MA (1992) Vitamin C intake and mortality among a sample of the United States population. Epidemiology 3, 194-202.

GISSI-Prevenzione Investigators (1999) Dietary supplementation with n-3 polyunsaturated fatty acids and vitamin $\mathrm{E}$ after myocardial infarction: results of the GISSI-Prevenzione trial. Lancet 354 (9177), 447-455.

Golden MHN, Ramdath DD \& Golden BE (1991) Free radicals and malnutrition. In Essential Trace Elements in Antioxidant Processes, pp. 199-221 [IE Dreosti, editor]. Totowa, NJ: The Humana Press Inc.

Halliwell B (1996a) Oxidative stress, nutrition and health. Experimental strategies for optimization of nutritional antioxidant intake in humans. Free Radical Research 25, 57-74.

Halliwell B (1996b) Vitamin C: antioxidant or pro-oxidant in vivo? Free Radical Research 25, 439-454.

Halliwell B (1999) Establishing the significance and optimal intake of dietary antioxidants: the biomarker concept. Nutrition Review 57, 104-113.

Halliwell B (2000) The antioxidant paradox. Lancet $\mathbf{3 5 5}$, 1179-1180.

Halliwell B \& Gutteridge JMC (1992) Biologically relevant metal ion-dependent hydroxyl radical generation. An update. FEBS Letters 307, 108-112.

Halliwell B \& Gutteridge JMC (1999) Free Radical Biology and Medicine, 3rd edition. Oxford: Oxford University Press.

Hennig B, Toborek M \& McClain CJ (1996) Antiatherogenic properties of zinc: implications in endothelial cell metabolism. Nutrition 12, 711-717.

Jabs T (1999) Reactive oxygen intermediates as mediators of programmed cell death in plants and animals. Biochemical Pharmacology 57, 231-245.

Jankowski MA, Uriu-Hare JY, Rucker RB, Rogers JM \& Keen CL (1995) Maternal zinc deficiency, but not copper deficiency or diabetes, results in increased embryonic cell death in the rat: implications for mechanisms underlying abnormal development. Teratology 51, 85-93.

Kardinaal AF, Kok FJ, Ringstad J, Gomez-Aracena J, Mazaev VP, Kohlmeier L, Martin BC, Aro A, Kark JD \& DelgadoRodriguez M (1993) Antioxidants in adipose tissue and risk of myocardial infarction: the EURAMIC Study. Lancet 342, 1379-1384.

Keusch GT (1990) Micronutrients and susceptibility to infection. Annals of the New York Academy of Sciences 587, 181-188.

Knutson MD, Walter PB, Ames BN \& Viteri FE (1999) Both iron deficiency and daily iron supplements increase lipid peroxidation in rats. Journal of Nutrition 130, 621-628.

Kramer JH, Misik V \& Weglicki WB (1994) Magnesium deficiency potentiates free radical production associated with post-ischemic injury to rat hearts: vitamin $\mathrm{E}$ affords protection. Free Radical Biology and Medicine 16, 713-723.

Kraus A, Roth HP \& Kirchgessner M (1997) Influence of vitamin $\mathrm{C}$, vitamin $\mathrm{E}$ and beta-carotene on the osmotic fragility and the primary antioxidant system of erythrocytes in zinc-deficient rats. Archives fur Tierernahrung 50, 257-269.

Kwik-Uribe CL, Golubt MS \& Keen CL (1999) Behavioural consequences of marginal iron deficiency during development in a murine model. Neurotoxicology \& Teratology 21, $661-672$

Lebovitz RM, Zhang H, Vogel H, Cartwright J Jr, Dionne L, Lu N, Huang S \& Matzuk MM (1996) Neurodegeneration, myocardial injury and perinatal death in mitochondrial superoxide dismutase-deficient mice. Proceedings of National Academy of Sciences, USA 93, 9782-9787.

McLaran CJ, Bett JH, Nye JA \& Halliday JW (1982) Congestive myocardiopathy and haemochromatosis - rapid progression possibly accelerated by excessive ingestion of ascorbic acid. Australian and New Zealand Journal of Medicine 12, 187-188.

Melov S, Schneider JA, Day BJ, Hinerfeld D, Coskun P, Mirra SS, Crapo JD \& Wallace DC (1998) A novel neurological phenotype in mice lacking mitochondrial manganese superoxide dismustase. Nature Genetics 18, 159-163.

Olin KL, Shigenaga MK, Ames BN, Golub MS, Gershwin ME, Hendrickx AG \& Keen CL (1993) Maternal zinc influences DNA strand break and 8-hydroxy-2'-deoxyguanosine levels in infant rhesus monkey liver. Proceedings of the Society for Experimental Biology and Medicine 203, 461-466.

Oteiza PI, Olin KL, Fraga CG \& Keen CL (1995) Zinc deficiency causes oxidative damage to proteins, lipids and DNA in rat testes. Journal of Nutrition 125, 823-829.

Pace GW \& Leaf CD (1995) The role of oxidative stress in HIV disease. Free Radical Biology \& Medicine 19, 523-528.

Peterhans E (1997) Oxidants and antioxidants in viral diseases: disease mechanisms and metabolic regulation. Journal of Nutrition 127 (5 Suppl), 962S-965S.

Postma NS, Mommers EC, Eling WM \& Zuidema J (1996) Oxidative stress in malaria; implications for prevention and therapy. Pharmacy World \& Science 18, 121-129.

Rao J \& Jagadeesen V (1996) Lipid peroxidation and activities of antioxidant enzymes in iron deficiency and effect of carcinogen feeding. Free Radical Biology and Medicine 21, 103-108.

Rayssiguier Y, Durlach J, Gueux E, Rock E \& Mazur A (1993) Magnesium and ageing. I Experimental data: importance of oxidative damage. Magnesium Research 6, 369-378.

Rehman A, Collis CS, Yang M, Kelly M, Diplock AT, Halliwell B \& Rice-Evans C (1998) The effects of iron and vitamin C cosupplementation on oxidative damage to DNA in healthy volunteers. Biochemical Biophysics Research Communications 246, 293-298.

Reizenstein P (1991) Iron, free radicals and cancer. Medical Oncology and Tumour Pharmacotherapy 8, 229-233.

Riemersma RA, Wood DA, Macintyre CC, Elton RA, Gey KF \& Oliver MF (1991) Risk of angina pectoris and plasma concentrations of vitamins $\mathrm{A}, \mathrm{C}$ and $\mathrm{E}$ and carotene. Lancet 337, 1-5.

Rowbotham B \& Roeser HP (1984) Iron overload associated with congenital pyruvate kinase deficiency and high dose ascorbic acid ingestion. Australian and New Zealand Journal of Medicine 14, 667-669.

Saari JT (1989) Chronic treatment with dimethyl sulphoxide protects against cardiovascular defects of copper deficiency. Proceedings of the Society for Experimental Biology and Medicine 190, 121-124.

Sandstead HH (1994) Understanding zinc: recent observations and interpretations. Journal of Laboratory and Clinical Medicine 124, 322-327.

Schwarz KB (1996) Oxidative stress during viral infection: a review. Free Radical Biology \& Medicine 21, 641-649.

Semba RD \& Tang AM (1999) Micronutrients and the pathogenesis of human immunodeficiency virus infection. British Journal of Nutrition 81, 181-189.

Stephens NG, Parsons A, Schofield PM, Kelly F, Cheeseman K \& Mitchinson MJ (1996) Randomised controlled trial of vitamin E in patients with coronary disease: Cambridge Heart Antioxidant Study. Lancet 347, 781-786.

Stewart BW (1994) Mechanisms of apoptosis: Integration of genetic, biochemical, and cellular indicators. Journal of the National Cancer Institute 86, 1286-1296. 
Sukalski KA, LaBerge TP \& Johnson WT (1997) In vivo oxidative modification of erythrocyte membrane proteins in copper deficiency. Free Radical Biology and Medicine 22, 835-842.

Taylor CG, Bettger WJ \& Bray TM (1988) Effect of dietary zinc or copper deficiency on the primary free radical defense system in rats. Journal of Nutrition 118, 613-621.

Toledo I, Aguirre J \& Hansburg W (1994) Enzyme inactivation related to a hyperoxidant state during conidiation of Neurospora crassa. Microbiology 140 (Pt 9), 2391-2397.

Turrens JF, Crapo JD \& Freeman BA (1984) Protection against oxygen toxicity by intravenous injection of liposome-entrapped catalase and superoxide dismutase. Journal of Clinical Investigation 73, 87-95.

Udenfriend S, Clark T, Axelrod J \& Brodie BB (1954) Ascorbic acid in aromatic hydroxylation. Journal of Biological Chemistry 208, 731-739.

Wilkins GM \& Leake DS (1994) The oxidation of low density lipoprotein by cells or iron is inhibited by zinc. FEBS Letters 341, 259-262.
Young IS, Trouton TG, Torney JJ, McMaster D, Callender ME \& Trimble ER (1994) Antioxidant status and lipid peroxidation in hereditary haemochromatosis. Free Radical Biology and Medicine 16, 393-397.

Winterbourn CC (1985) Free radical production and oxidative reactions of haemoglobin. Environmental Health Perspectives 64, 321-330.

Zidenberg-Cherr S, Keen CL, Lonnerdal B \& Hurley LS (1983) Superoxide dismutase activity and lipid peroxidation in the rat: developmental correlations affected by manganese deficiency. Journal of Nutrition 113, 2498-2504.

Zidenberg-Cherr S \& Keen CL (1991) Trace Elements, micronutrients, and free radicals. In Essential Trace Elements in Antioxidant Processes, pp. 107 [IE Dreosti, editor]. Totowa, NJ: The Humana Press Inc.

Zidenberg-Cherr S, Han B, Dubrick MA \& Keen CL (1991) Influence of dietary induced copper and manganese deficiency on ozone-induced changes in lung and liver antioxidant systems. Toxicology Letters 57, 81-91. 